\title{
THE EFFECTS OF THE PANDEMIC ON THE ENTREPRENEURSHIP FROM THE ROMANIAN AGRIFOOD SECTOR
}

\author{
DOI: 10.17261/Pressacademia.2021.1412 \\ PAP- V.13-2021(1)-p.1-5
}

Mioara Mihăilă ${ }^{1}$, Carmen-Luiza Costuleanu ${ }^{2}$, Andy-Felix Jităreanu ${ }^{3}$

${ }^{1}$ Alexandru loan Cuza University of lasi and Ion lonescu de la Brad lași University of Life Sciences, Agroeconomics, lași, Romania. mioara@uaic.ro, mioara@uaiasi.ro, ORCID:0000-0002-8185-0976

${ }^{2}$ Ion Ionescu de la Brad Iași, University of Life Sciences, Agroeconomics, Iași, Romania. costuleanu.carmen@uaiasi.ro, ORCID: 0000-0003-0071-4241

${ }^{3}$ Ion lonescu de la Brad Iași, University of Life Sciences, Agroeconomics, Iași, Romania. andyj@uaiasi.ro, ORCID: 0000-0001-5807-1790

\section{To cite this document}

Mihăilă, M., Costuleanu, C.L., Jităreanu, A.F., (2021). The effects of the pandemic on the entrepreneurship from the Romanian agrifood sector. PressAcademia Procedia (PAP), V.13, 1-5.

Permanent link to this document: http://doi.org/10.17261/Pressacademia.2021.1412

Copyright: Published by PressAcademia and limited licensed re-use rights only.

\section{ABSTRACT}

Purpose- The purpose and the objectives of this paper are the identification of the main effects and measures in the Romanian agri-food sector, linked to the generalized pandemic context generated by "Covid-19", that affected all economics areas.

Methodology- The paper is an empirical and practical research, based on the hypothesis that the vital economic sectors it can resist to the pressure of a global crisis, such as of 2020 pandemic. The main methods used are observation, data collection, analysis and synthesis. With the presentation of data, reports and information relevant for the topic related to the pandemic effects in the Romanian agri-food sector, we present the main effects, and measures for decreasing these effects of the pandemic with specificity for the entrepreneurial area from the Romanian agri-food sector. We develop an incursive research to emphases the arguments regarding the vital role of the agri-food sector in the humanity development and economic growth.

Findings- The analysis reveals that not always a critical situation, like this crisis, is dangerous in the long-term and for all sectors. The results of the paper indicates that even the Romanian agri-food sector was serious affected by this pandemic, the activity was blocked only in the short term and the government taken appropriate measures to ensure the labour continuity, because here is produced the food - the support for the life continuity.

Conclusion- Based upon the analysis it may be concluded that the vital economic sectors can overpass the difficult periods and can resist to the market shocks. Also, by some personal opinion based on our hypothesis, we conduct to the relevant conclusion about the resilience of a vital sector for the entire economy, and this is the agri-food sector.

Keywords: Pandemic, agri-food, recovery, farmer's support.

JEL Codes: D50, M10, Q18

\section{INTRODUCTION}

The Romanian agri-food sector has experienced a significant development process in the last about 5 years, with a major focus on the domestic production and commercializing the domestic products. The European funds, together with the initiatives and dynamism of the entrepreneurs in this sector, have contributed to this growth.

Through this paper we propose to underline the effects of the pandemic caused by "Covid-19" that hovered on the evolution of this sector. However, it is important to note that, being the basic economic branch, despite all the pandemic impediments, the agri-food sector has been less affected - and for Romania this a preliminary post-pandemic conclusion. Also, according to the well-known Maslow's Pyramid, the food needs are primordial and, regardless of the more or less difficult periods, they must to be satisfied.

The main arguments for the topic of this paper, developed as a practical approach starting from the observation of the nowadays reality with the pandemic impact on the overall area of life, is that the agri-food sector is one of the most important for the contribution to the economic development, and moreover, we consider that it is vital and primordial in the process of the human evolution. As long as there is life on Earth, the agri-food sector will be a priority regardless of the rhythm of the technological advancement. 
As motivation for this research, we developed concerns and interest for the agri-food sector, now affected by the "Covid-19" pandemic crisis, but by other crisis, too, during the historical times. Another motivation is the scientific belief that the disruptive events, despite slowing the progress, can emphasize the importance and vitality of that sector, through collective efforts to minimize certain deficiencies. The scientific curiosity supported by the hands-on study of the effects of the pandemic is satisfied with the analysis of some issues in the agri-food sector, despite long being in the area of study and research, proves to be always of actuality.

By the present paper we emphasize the effects of the pandemic which have lingered over the evolution of the agri-food sector and the measures meant to diminish and correct the vulnerabilities of this sector. Also, is important to mention that, as a main economic sector, this has been less affected in Romania, despite all the obstacles of the pandemic, along with the weather conditions.

\section{LITERATURE REVIEW}

In the specialty literature, there are many studies about the agriculture importance, evolution and development, and for the agri-food sector, too. Both the national and international literature are very rich, because this sector is a strategic one for the biggest economies from the world. Being a practical research, based mainly on reports and data, we split the literature approached in two parts: the literature about the agri-food sector and the literature for the pandemic. The first is very well represented, and is very large and complete. For the Romanian agriculture, we found many reports that indicates the favourable evolution of this sector. Among the most relevant: The Annual Report to implement the National programme for Rural Development, for 2014-2020 period, The General Agricultural Census 2020, the articles and press releases of the National Institute of Statistics, but the reports and data from international level - Eurostat, FAO, World Bank. The main books and article are especially of the autochthonous autors: Otiman, P.I., Toderoiu, F., Luca, L., Gavrilescu, D., Bohatereț, V.M. etc.

The topic of the pandemic, which still proves to be of the actuality, has attract the interest from the academic world as well as practitioner from all areas of life science. The shock of the pandemic started in 2020 has changed all areas of life, and the Romanian agri-food sector was no exception. The literature on the effects of a pandemic on the agri-food sector, for the moment is barren, because the phenomenon is new, so not yet presented in publishing houses. For this research we used information from the press releases and official institutions as World Health Organization, OECD, Eurostat, United States Department for Agriculture, etc. that hold recent publications, 2020 -2021, in this field, but without many references because the statistics are not concretized yet, even the World Economic Forum and the European Commission have references to the socio-economic aspects of the pandemic effects. Literature for the pandemic impact on the Romanian agri-food sector is poor for the moment, and emphases the results and effects of this crisis on the entrepreneurial area, but the data are not well represented in books or papers, only in journals and statistics.

\section{DATA AND METHODOLOGY}

The research of this paper is a qualitative one, supported by statistics and data from the official reports. The methods used are: observation, analysis and synthesis. Based on observation and scientific curiosity, we formulated the hypothesis that some big crisis, as this of the pandemic of "Covid-19", can highlights the power of a basic sector, that can survive after some disasters. Then, we found and collect the data and information from the national and international reports, to confirm or not our hypothesis. Also, we made a synthesis, based on grouping and connection between data. The used data are from the National Institute of Statistics, Romanian Academy, Ministry of Agriculture and Rural Development and Eurostat. The main directions approached for the data collection and analysis are specific for the agri-food sector development and for the pandemic impact on it. For this practical research based on data and reports analysis, our main goal is to show the endurance of the vital sectors, as the agri-food one, in confrontation with some global crises, such as the "Covid-19" one, started in 2020.

\section{FINDINGS}

As we know from the day-by-day life, nowadays, the condition of the whole world is directly affected by the action of the "Covid-19" phenomenon, surprising in its rapid propagation and multiplier effects. The pandemic caused by "Covid-19" determined, in a very short time, an overwhelming impact in all spheres of the human life. So, the empirical research, approached as a practical study, shows the impact of the pandemic phenomenon on the Romanian agri-food sector. The pillar for the management of the pandemic crisis in this analysed sector are the actors involved in the support and development of the Romanian agri-food sector: farmers, processors, delivery people, distributers. (Ministry of Agriculture, 2015)

In Romania, this strategic sector, severely affected by the pandemic crisis of "Covid-19" from 2020, has been strongly supported by key instruments and solid measures, during the pandemic period, starting in the spring of 2020 until nowadays.

The phenomenon is overlapping with a strong campaign meant to encourage the consumption of local products, campaign initiated around 2 years before the pandemic crisis start.

The general presentation of the Romanian agri-food sector in the context of the "Covid-19" pandemic appearance in 2020:

- around 25,000 companies involved in the national agriculture

- all entrepreneurial areas very well represented for: crops, vegetables, zootechnic, horticulture etc.

around $20 \%$ of employees are involved in the agriculture and agri-food sector

- $\quad 3.8 \%$ contribution to the GDP 
- $\quad$ around 3 million ha. cultivated in the autumn of 2019, but severely affected by the pandemic crisis

- $\quad$ Romania is among top wheat, corn and barley sellers in EU, providing markets in North Africa and the Middle East

- $\quad$ in 2018 and 2019, Romania was the $1^{\text {st }}$ in the EU for sunflower and corn production

- $\quad$ in 2020 the crops production decreased by $50 \%$

The main general characteristics of entrepreneurs in the national agri-food sector are: commitment, responsibility, professionalism, solidarity. (Ministry of Agriculture, 2015)

In some researches of the specialized institutions, among which the Romanian Academy, two distinct periods of time have been identified right after the start of the pandemic and the specificities of each one (Alexandri, C. \& all., 2020):

1. The time of panic sales, in the first weeks of the pandemic: increased sales especially for non-perishable products - grains, cans, oil, certain types of cheese etc. The demand for wheat flour, corn flour and cooking oil has risen, right after the start of "Covid-19", by approximately $50 \%$, which represented a challenge for all supply chains.

Between 23 February and 15 March 2020, the following sales evolution was found:

- $\quad$ retail sales: raised by $37.2 \%$

- food products sales: raised by $42 \%$ (meat, sausages, oil, cheese, water, fruits, vegetables and cans)

- growth of over 350\%: meat cans (625\%), pure alcohol (418\%), baking yeast (366\%)

All those numbers indicate a general panic related to the crises which violate food safety and security.

2. Extended lockdown period, generally marked by:

- a decrease in the demand for many products, due to restricted physical access in markets or stores or traffic restrictions

- a cut in income, which results in the decrease of the sale for more expensive products that have a higher nutritional value vegetables, fruits, meat; consumption of these products has also been affected by the decline in consumption outside the household, caused by limited access to restaurants, bars and outdoor pub areas

The pandemic crisis (2020 - 2021) has shocked the vegetables-fruits sector as the producers haven't been organised in collaborations and haven't had any contracts with the retailers or processing factories. The vegetable market had issues especially with the sale of production during the lockdown months. Less than $1 \%$ of producers are part of groups or organisations, the EU average being $45 \%$. The reluctance to form associations, poor counselling and the lack of understanding the advantages of collective market organisation are factors that have amplified the disruption following the crisis. During the pandemic crisis, imports have continued to rise. The required consumption isn't totally ensured from internal resources, and farmers have limited their production. Vegetable production has witnessed a major decline (2020) resulting from a decrease in demand but also as a result of drought. Drought and lack of investments in the infrastructure have brought a decrease by $15 \%$ in turnover, from 9,345,774 Euro in 2019, at 7,923,591 Euro in 2020. (Nica, M., 2020)

The"Covid-19" crisis has accentuated the instability and volatility of average production and prices and will continue to do so. Even though work in the agri-food sector has never stopped, significant losses have been registered through diminished activity of farmers and production sale blockage. The government has suspended for a week (in April 2019) the grain exports to other non-EU destinations, after it was found that in March, 700,000 tons of grains had been exported, in order to ensure that the necessary quantity of wheat for internal consumption and food security for Romania will not be affected.

There are, also, issues related to the acquisition of inputs. Overall, the farmers have estimated losses of around $50 \%$ following the blockages caused by the pandemic. The average yields per hectare, decreased in 2020 compared to 2019 by about $40 \%$ for cereals, $60 \%$ for oil plants and $45 \%$ for vegetables. Other results in dynamics:

- fruit sector: average production is down by about $31 \%$

- yields per hectare for grapes decreased in 2020 by about 6\% compared to 2019

- livestock sector: livestock decreased by $1.42 \%$ in cattle, by $1.26 \%$ in sheep / goats, by $3.99 \%$ in pigs, $14.66 \%$ in birds and $0.90 \%$ in bee families

The Table 1 highlight the dynamic of the grain production in 2020 - the year of the pandemic phenomenon with big influence on the agricultural production, compared to 2019 when the Romanian agri-food sector registered a very good or satisfactory production. 
Table 1: The Grain Production Dynamics in 2020 Compared to 2019

\begin{tabular}{|l|c|c|}
\hline Cultures (m.u.) & $\mathbf{2 0 1 9}$ & $\mathbf{2 0 2 0}$ \\
\hline Total cereals production (millions tons) & 30,4 & 17,03 \\
\hline Wheat (millions of tons) & 14,856 & 6,091 \\
\hline Barley (tons) & $1,340,000$ & 727,377 \\
\hline Barley girl (tons) & 539,558 & 279,039 \\
\hline Oat (tons) & 361,573 & 187.522 \\
\hline Sunflower (millions of tons) * in 2019 the biggest production from the EU & 3,56 & 1,84 \\
\hline Rape (tons) & 798,215 & 663,710 \\
\hline Corn grain (millions of tons) & 17,43 & 9,63 \\
\hline
\end{tabular}

Source: personal synthesis based on the data of the National Institute of Statistic, Press release, nr. 80/31.03.2021

But there is good news related to the impact of the pandemic on the Romanian agri-food sector, because the government and other authorities, take many and various measures to reduce the effects of the pandemic. So, the representatives of the agri-food sector have constantly worked to ensure the stability of the entire specific chain, as it is vital for the population to be ensured the goods indispensable to life: the food. (Cavescu, A., 2020) The Ministry of Agriculture guarantees compensation to all farmers affected by this event and as a member of the European Union, Romania is on the list of countries that benefits from the support of the European Commission for overcoming the effects of the pandemic in the agri-food sector. (European Commission, 2020). Among the most important measures taken as a defensive response to the pandemic crisis (The Journal of European Union, L140, 2020):

- Help for the private storage of dairy products and meat products (temporary withdrawal from the market for a minimum of 2-3 months and a maximum of 5-6 months; the measure led to the decrease of the available offer on the market and the rebalancing of the market on the long term)

- Flexibility in the support schemes for the wine, fruits, vegetables and olive oil markets and for beekeeping and a support scheme for schools (milk, fruits and vegetables)

- Exempt from certain EU norms in terms of competition: applied to the milk, flowers and potatoes sectors. In actuality: collective plans for milk production, withdrawal of flowers and potatoes from the market.

Governmental schemes created to support the farmers and young farmers, by the European funds, and the "SMEs invest" scheme, for the small and medium enterprises: loans with an interest rate subsidized per work capital or investment, with a total budget of 161 million Euro, subsidizing the insurance premium for the plant sector by $70 \%$ for standard risks.

Other support actions to overcome the effects of the pandemic in the Romanian agri-food sector:

- $\quad$ support for the small organic businesses, both for producers and sellers

- $\quad$ promoting the local farmers and the national entrepreneurship

- growing the demand for the local products by the national campaigns to support the domestic producers

- encouragement of schools or other institutions to sign contracts for the acquisition of the organic products collective association of small farms to overpass all together the difficult crisis period

Among the first measures taken by the Ministry of Agriculture and Rural Development (MARD \& Nica, M., 2020), considered for the emergency period, in order to avoid the panic and social reactions due to the possible lack of food, are:

- monitoring of shelf prices for basic food products, of food supplies and of inputs by economic operators, to avoid a possible food crisis

- the creation of an online communication platform in an associative context up to date

- creation of an online platform dedicated to small producers of vegetables

- "Measure 21" has been implemented as part of NPRD 2014-2020 (National Programme for Rural Development) - temporary support of an exceptional nature for farmers and SMEs affected by COVID-19 crisis, with a budget of 59,5 million Lei, respectively 11.987 .561 Euro

- $\quad$ the Ministry has continued the financial support for the farmers in the vegetables and zootechnic sectors

- creation the National Resilience and Recovery Plan which includes some areas for the agri-food sector, for example a subvention with 6.5 billion Euros in water management infrastructure 
The long terms programs, plans and strategies for the Romanian agri-food sector include, also, measures and initiatives to help the entrepreneurs from the agri-food sector to overpass this difficult period. The most important are: the 2020-2024 Government Programme and the Government Programme to support the young farmers. We consider that for Romania, the effect was somewhat contradictory, because this pandemic crisis brought the agriculture back to the forefront, along with awareness of the vital role of the sector on which the food production depends. (Cavescu, A., 2020)

\section{CONCLUSION}

In the Romanian agri-food sector the effects of the" Covid-19" crisis with the associated pandemic phenomenon can be considered paradoxical, because this pandemic has brought agriculture in the centre of attention of the government and other national responsible authorities, together with the international partners, along with the awareness of the vital role of the sector responsible for the food production.

Other favourable and unexpected effects are: the chance to cover the work deficit in the agri-food Romanian sector by the return of the Romanians that went to work abroad, the possibility to promote and commercialize Romanian food products, starting some activities online - including the sale of agri-food products, which, in the long-term, lead to the development of a niche sector.

Although Food and Agriculture Organization (FAO) has warned about the risks of a food crisis that would first affect small and medium farmers, in Romania this risk has been limited and for short term, entrepreneurial work being restarted at the moment. The dysfunctionalities in the entire agri-food system composed by farms, supply chains, agri-food demand and the consumption behaviour of the Romanians, have been identified and covered by measures and consistent support and it has been proven that farmers, together with authorities, can find solutions for organizing production and supply chains. Romania hasn't been in the middle of a food crisis, and the green routes of food products and inputs are working at normal rates at present. The study of the effects of the pandemic crisis proves to be of maximum utility, as it is linked to the measures associated with the consequences for the near future (2021-2022): inflation, decrease in production, reconsideration of import-export relations. The pandemic context imposes the reconsideration of human needs, along with the revival of strategies, budget allocation, implementing of actions and special measures for overcoming the crisis.

The revival of the agri-food sector is a first-class priority. The Romanian agri-food sector has known a significant process of development between 2014-2019, with major focus on production and commercialization of local products. The European funds, along with the initiatives and dynamics of entrepreneurs in this sector, have contributed to this significant growth in Romania's economic development.

But in the end, is important to highlight some limits of this paper, because the time too short between the effects manifestation and the scientific papers publication alters the relevant conclusions, without solid forecasts. The lack of many data and the poor literature about the pandemic, does not allow the generalization of the results. We propose to extend this research in the future, in order to improve this limits.

\section{REFERENCES}

Alexandri, C. (coord.), Rusu, M., Tudor, M.M., Luca, L. et all., (2020). The agricultural sector and the rural environment in the Covid-19 crisis: the challenge of food security, Romanian Academy, Agrarian Economy Institute, Bucharest, report available at https://acad.ro/SARS-CoV2/doc/d17-Sectorul_agricol_mediul_rural.pdf, accesed on $6^{\text {th }}$ of May 2021

Cavescu, A. (2020). The COVID crisis and drought - major impact in the agri-food sector, a press release article published on $28^{\text {th }}$ of April 2020, available at https://www.greco.services/ro/news/agri-covid.html accessed on 24th of April 2021

Nica, M. (2020), Retrospective 2020. Romanian agriculture shaken by pandemic and drought, article available at https://www.agerpres.ro/economic-intern/2020/12/28/retrospectiva-2020-agricultura-romaniei-zdruncinata-de-pandemie-si-seceta-634468 and accesed on 3rd of May 2021

European Commission (2020). Coronavirus: the Commission adopt a package of measures to provide more support to the agri-food sector. A press release, Bruxelles, $4^{\text {th }}$ of May 2020, available at https://ec.europa.eu/commission/presscorner/detail/ro/IP 20_788

Ministry of Agriculture and Rural Development. Annual report on the implementation of the National Rural Development Program for the period 2014 - 2020. The European Agicultural Funds for Rural Development, Europe Investing in Rural Areas, 2020.

Ministry of Agriculture and Rural Development. Strategy for the development of the agri-food sector in the medium an dlong term: horizon 2020-2030. We intelligently capitalize on Romania's agri-food potential. Bucharest, 2015

National Institute of Statistics (2020). Covid-19. Economic impact, articles available at https://insse.ro/cms/en/covid-19-impactul-economic, accesed on $24^{\text {th }}$ of May 2021

OECD (2020). OECD Policy Responses to Coronavirus. The impact of Covid-19 on agricultural markets and GHG emissions, article available at https://www.oecd.org/coronavirus/policy-responses/the-impact-of-covid-19-on-agricultural-markets-and-ghg-emissions-57e5eb53/

Official Journal of the European Union, L140. Vol. 63/4.05.2020, available at https://eur-lex.europa.eu/legalcontent/RO/TXT/PDF/?uri=OJ:L:2020:140:FULL\&from=RO 